\title{
Educação Física, cultura e escola: da diferença como desigualdade à alteridade como possibilidade
}

\author{
Rogério Cruz de Oliveira* \\ Jocimar Daolio**
}

\begin{abstract}
Resumo: Este estudo objetiva compreender como as diferenças são significadas e representadas pelos alunos nas aulas de educação física. Trata-se de uma etnografia desenvolvida numa escola pública do município de Campinas-SP. Tal incurso levou-nos à compreensão de que as diferenças apresentadas pelos alunos constituíram parâmetros definidores de desigualdade de oportunidades, preconceitos e sectarismos. Assim, o entendimento das diferenças esteve permeado por certos reducionismos, enxergando o "outro" somente por suas características mais visíveis, obscurecendo a complexidade da dinâmica cultural. Por fim, compreendemos que é desejável que as diferenças sejam consideradas na ótica da alteridade subsidiada por uma perspectiva intercultural de educação.

Palavras-chave: Educação Física. Educação. Preconceito. Identidade de gênero.
\end{abstract}

\section{INTRODUÇÃO}

Imaginemos uma escola em horário letivo: professores ministrando aulas, alunos atentos, silêncio nos corredores, somente quebrado quando algum aluno se desloca pelo mesmo; no pátio, alguns funcionários a serviço da limpeza; na cozinha, funcionários preparando a merenda escolar; na secretaria, algumas pessoas concentradas no trabalho burocrático, ora atendendo a comunidade, ora dando conta de alguns papéis e, na quadra, uma aula de educação física (EF): alunos afoitos, professor(a) atento(a), o silêncio é substituído por um constante diálogo de todos com todos - ao mesmo tempo. Pausa para água, diálogo com o(a) professor(a) e retorno à atividade corporal.

\footnotetext{
* Doutorando em Educação Física. Faculdade de Educação Física. Universidade Estadual de Campinas. Campinas, SP, Brasil. E-mail: rcruzoliveira@gmail.com

** Professor Livre-Docente. Faculdade de Educação Física. Universidade Estadual de Campinas. Campinas, SP, Brasil. E-mail: jocimar.daolio@gmail.com
} 
Talvez essa descrição não represente a realidade de algumas escolas, no entanto, é comum em muitas outras. Feita assim, de forma rápida, parece que não existe novidade a ser dita sobre o cotidiano escolar, muito menos sobre a aula de EF neste. No entanto, primandose esse olhar, mais amplo e distanciado, corre-se o risco de deixar de lado a dinâmica cultural, percebida por um olhar "de perto e de dentro", em alusão a Magnani (2002). Um olhar de perto e de dentro nos coloca a par da dinâmica dos atores sociais que fazem parte de diversos contextos simbólicos, fazendo-nos enxergar a complexa teia cultural que os envolve.

Assim, este estudo objetiva compreender como as diferenças ${ }^{1}$ são significadas e representas pelos alunos em aulas de EF. A intenção é possibilitar o acesso a outros argumentos na direção do debate da diferença e da diversidade cultural na EF, tão em voga atualmente. De acordo com Geertz (1989), as ideias teóricas de novos estudos são adotadas de outros relacionados e, refinadas durante o processo, aplicadas a novos problemas interpretativos. "Os estudos constroem-se sobre outros estudos [...] eles mergulham mais profundamente nas mesmas coisas" (GEERTZ, 1989, p. 35).

\section{CAMINHO METODOLÓGICO}

A investigação está delineada como uma etnografia, no sentido de uma "descrição densa", conforme Geertz (1989). Foi realizada numa escola da Rede Estadual de Educação de São Paulo (REE/SP), no município de Campinas. Os dados foram coletados durante um bimestre letivo por meio de observação das aulas de EF de uma $8^{\mathrm{a}}$ série, bem como de entrevistas não estruturadas com professora e alunos.

No bimestre em que a pesquisa foi realizada (agosto e setembro de 2005), o conteúdo contemplado foi o voleibol. Das 16 aulas previstas,

\footnotetext{
${ }^{1}$ A diferença é por nós entendida como uma categoria explicativa da diversidade cultural. Segundo Ortiz (2000), a diversidade cultural não pode ser vista como diferença. Segundo o autor toda diferença é produzida socialmente, é portadora de sentido simbólico e histórico. Se considerado somente o sentido simbólico, corre-se o risco de isolar-se num relativismo pouco consequente. Afirmar o sentido histórico da diversidade cultural é submergi-la na materialidade dos interesses e dos conflitos sociais (ORTIZ, 2000). A diversidade manifesta-se, pois, em situações concretas, delineadas neste estudo.

Movimento, Porto Alegre, v. 16, n. 01, p. 149-167, janeiro/março de 2010.
} 
a observação ocorreu em 12. A intenção era buscar decifrar "estranhos" códigos, ler entrelinhas, perceber comportamentos, "pescar" discursos e falas, interpretar significados, enfim, filtrar o dito e o não dito pelos atores sociais no que se refere ao objetivo do estudo (OLIVEIRA; DAOLIO, 2007). Este intento mostrou-se necessário na medida em que, segundo Geertz, a cultura, como "sistema entrelaçado de signos interpretáveis",

[...] não é um poder, algo ao qual podem ser atribuídos casualmente os acontecimentos sociais, os comportamentos, as instituições ou os processos; ela é um contexto, algo dentro do qual eles podem ser descritos de forma inteligível-istoé, descritos com densidade. (GEERTZ, 1989, p. 24)

Nesta direção, buscou-se contemplar as quatro características de uma etnografia, ou "descrição densa", colocadas por Geertz: 1. uma etnografia é interpretativa; 2 o que ela interpreta é o fluxo do discurso social; 3. a interpretação envolvida consiste em tentar salvar o "dito" num tal discurso da sua possibilidade de extinguir-se e fixá-lo em formas pesquisáveis e 4. ela é microscópica.

Estas ações estão em consonância com o que o autor chama de "especificidade complexa", ou "circunstancialidade". É justamente com essa espécie de material produzido por um trabalho de campo, principalmente qualitativo, altamente participante e realizado em contextos "confinados", que os "megaconceitos" podem adquirir toda espécie de atualidade sensível que possibilita pensar não apenas, realista e concretamente, sobre eles, mas, criativa e imaginativamente, com eles (GEERTZ, 1989).

\section{A escola pesquisada e as aulas de Educação Física}

A escola não é algo à parte da vida dos sujeitos mas, sim, parte de seus projetos pessoais, que, ao depositarem nela aspirações diversas, fazem com que a mesma tenha legitimidade social que a valorize como instituição formadora. Segundo Gusmão (2003), a escola é um espaço de sociabilidades, de encontros e desencontros, de buscas e perdas, de descobertas e encobrimentos, de vida e negação da vida. Trata-se de um espaço sociocultural.

Movimento, Porto Alegre, v. 16, n. 01, p. 149-167, janeiro/março de 2010. 


\section{Astigos Originais Rogério Cruz de Oliveira e Jocimar Daolio}

Neste sentido, de acordo com Dauster (1996), parece ser a escola uma instituição privilegiada que, na medida em que possibilita o contato entre atores com diferentes visões de mundo, promove o encontro e a troca de vivências e significados percebidos no cenário escolar pesquisado.

A escola pesquisada é dotada de grande estrutura, ocupando um quarteirão inteiro, cercada por muro não muito alto. Atende a três bairros, não sendo caracterizados como nobres ou de periferia, ligados uns aos outros, constituindo uma microrregião ao norte da cidade.

A organização interna da escola é estruturada em três prédios e duas quadras de esportes - ambas separadas por extenso alambrado ${ }^{2}$ - acessadas somente por um portão, que permanece quase todo o tempo trancado com corrente e cadeado. $\mathrm{O}$ acesso às quadras é feito somente em horários de aula de $\mathrm{EF}$, mediante a presença de professores.

Em relação às aulas de EF, estas não fugiram à percepção inicial de um momento muito aguardado pelos alunos. É comum observarmos nas escolas a euforia com que os alunos se encaminham para uma aula de EF:

$$
\begin{aligned}
& \text { "Não é raro vermos os alunos sedentos pelas aulas } \\
& \text { de educação física, demonstrando verdadeiras explo- } \\
& \text { sões de alegria e alívio quando saem da sala de aula. } \\
& \text { O gosto ou a espera pela educação física, nesse caso, } \\
& \text { ficam mesclados com as necessidades de viver outras } \\
& \text { relações na escola." (AYOUB, 2005, p. 2264). }
\end{aligned}
$$

Neste estudo, foi observada em todas as aulas certa aglomeração no portão de acesso às quadras antes do início. A espera pela professora de EF começava após o término do recreio, ${ }^{3}$ no entanto, alguns alunos já se encontravam nas proximidades do portão antes mesmo deste período.

A turma da $8^{\mathrm{a}} \mathrm{B}$ era composta por 36 alunos, sendo 15 meninos e 21 meninas, com idades entre 14 e 17 anos. De acordo com a professora de EF, tratava-se de uma turma difícil e problemática. Este con-

\footnotetext{
${ }^{2}$ Segundo a professora, a existência do alambrado impede que os alunos ociosos perturbem o desenvolvimento de suas aulas, bem como impede que a bola atinja as pessoas que não participam da aula, evitando maiores contratempos.

${ }^{3}$ As aulas dessa turma aconteciam logo após o recreio.

Movimento, Porto Alegre, v. 16, n. 01, p. 149-167, janeiro/março de 2010.
} 
ceito devia-se, segundo as observações feitas, em seus comentários de professora, a "desrespeitos" que os alunos tinham entre si e, às vezes, até com ela: "É uma turma que se tem que ter muita paciência, perseverança."

A $8^{\mathrm{a}} \mathrm{B}$ tinha duas aulas de EF por semana, com duração de cinquenta minutos cada uma, a critério da professora, mas estavam reunidas num só dia: "[...] era melhor trabalhar com duas aulas reunidas, pois cinquenta minutos era pouco tempo" (professora).

As aulas de EF obedeciam a uma tradicional rotina. Apesar de serem mistas, a professora dividia a turma por sexo. Segundo ela, era mais fácil trabalhar com grupos homogêneos pois tanto os meninos quanto as meninas sentiam-se mais à vontade. Afirmou que no início de sua carreira docente esta divisão apresentava-se também para os professores. Homens ministravam aulas para turmas de garotos e mulheres, para turmas de garotas. De certa forma, a professora havia se acostumado a um modelo de aula. Também se reportou ao aspecto dos meninos serem mais fortes que as meninas, havendo a possibilidade destas se machucarem. Segundo Saraiva (2005), o cotidiano das aulas de EF, ministradas nas redes de ensino particular e público, ainda hoje é marcado por dificuldades e resistências à prática conjunta entre meninos e meninas, tanto por parte dos alunos quanto dos professores.

Ao dividir a turma, após um alongamento inicial, a professora ficava com um grupo na quadra coberta para a aula de voleibol e dirigia o outro grupo à quadra externa para jogarem futebol. Ao soar o sino da Escola, que sinalizava o término da aula, havia a inversão dos grupos.

Curioso notar que apesar do futebol ter sido contemplado como conteúdo de um bimestre anterior, ainda se encontrava presente nas aulas de todo o ano letivo. No entanto, a atenção e intervenção da professora ficavam restritas ao voleibol, deixando o "jogo" de futebol transcorrer como mera atividade recreativa ou de espera. Questionada sobre a razão da ênfase no futebol, a professora disse que se tratava de uma "paixão dos alunos" e que reclamariam se não o praticassem: "Eles só querem saber de futebol."

Já nas aulas de voleibol, cujo clima não era tão contagiante, a professora priorizava o jogo em si, dizendo que em outras turmas até trabalhava os fundamentos desse esporte como, por exemplo, o saque,

Movimento, Porto Alegre, v. 16, n. 01, p. 149-167, janeiro/março de 2010. 
154 Artifos Originais Rogério Cruz de Oliveira e Jocimar Daolio

o toque, a manchete etc., mas na $8^{\mathrm{a}} \mathrm{B}$, por se tratar de uma turma "difícil”, não o fazia: "Eles reclamariam!"

A professora dividia o grupo em dois times e iniciava o jogo, ficando à beira da quadra passando instruções e marcando os pontos. Havia certa flexibilidade com as regras do voleibol profissional, no entanto, este era o modelo.

Como a turma era dividida em dois grupos e duas práticas distintas (voleibol e futebol), optamos por acompanhar ambas, não buscando priorizar nenhuma. Ora na quadra interna, ora na quadra externa ou no trânsito entre as duas, a observação permitiu o fomento de percepções diversas sobre a temática do estudo, o que faremos a seguir.

No entanto, não no sentido de esgotá-las, pois, segundo Geertz (1989, p. 39), "A análise cultural é intrinsecamente incompleta e, o que é pior, quanto mais profunda, menos completa", mas na direção de um possível olhar sobre as mesmas.

De acordo com Fonseca (1999), "cada caso não é um caso", ${ }_{4}$ são os dados particulares que abrem caminhos para interpretações maiores. Conforme Geertz (1989, p. 31), as interpretações mais amplas e abstratas partem de um conhecimento extenso de assuntos extremamente pequenos.

\begin{abstract}
"Aliás, é justamente essa extensão de nossas análises a contextos mais amplos que, juntamente com suas implicações teóricas, recomenda-as à atenção geral e justifica nosso empenho em construí-las."(GEERTZ, 1989, p. 31)
\end{abstract}

\title{
4SOBRE DIFERENÇAS E DESIGUALDADES
}

$\mathrm{O}$ incurso a uma escola para observar aulas de EF de uma determinada turma, a $8^{\mathrm{a}} \mathrm{B}$, buscando entender como as diferenças são signi-

\footnotetext{
${ }^{4}$ Fonseca (1999) demonstra em seu trabalho que a filosofia relativista do "cada caso é um caso" não é equivalente com a etnografia, pois esta sempre vai além do caso individual. Em um de seus exemplos, há a explicitação do trabalho de um pesquisador que, dizendo ter realizado uma etnografia, utiliza-se de entrevistas quase terapêuticas em sua "pesquisa de campo". Frente ao fato, a autora explicita sua preocupação com aqueles que se aventuram pela antropologia, especificamente pela etnografia, sem preparação adequada, podendo, em vez de realizar uma costura interdisciplinar, cair no vazio - um território nem lá, nem cá, onde o que mais floresce é o senso comum da cultura do pesquisador. Assim, ela encaminha seu texto na direção de evidenciar que, em etnografia, "cada caso não é um caso".
}

Movimento, Porto Alegre, v. 16, n. 01, p. 149-167, janeiro/março de 2010. 
ficadas e representadas pelos alunos que compõem tal contexto, revelou-nos um quadro constituído de deformidades que extrapolavam o cotidiano local. As diferenças, ao serem observadas, serviram de parâmetros estabelecedores de desigualdades de oportunidades nas aulas, preconceitos e sectarismos, pautados por certos estereótipos.

Tal fato leva ao seguinte apontamento, que explicitaremos nas próximas linhas: parece que ainda paira no cotidiano das aulas de EF certo ranço "naturalista" - mesmo com todo avanço no debate sobre a cultura e compreensão das diferenças nos processos educativos, fomentado pela produção acadêmica no campo da educação e EF. ${ }^{6}$

Neste estudo, a exclusão, o preconceito e os estereótipos foram percebidos na atuação de alguns atores que encenaram este enredo. $\mathrm{O}$ fato de ser menina, ser gordinha ou ser menino com gestos e comportamentos do gênero feminino, ser negro ou, simplesmente, ser "grosso", acabaram por delimitar certas privações, sobre as quais discorreremos a seguir.

O embate entre menino e menina nas aulas foi um fato observado ao longo de toda a pesquisa. Ambos os sexos pareciam travar uma enorme "briga" por espaço e status. Um fato agravante para tal situação residiu na opção da professora pela divisão da turma proposta, comentada anteriormente. Se em sua intervenção a professora opta por separar meninos e meninas, a legitimidade do fato, consequentemente, é incorporada nas ações dos alunos.

Vê-se que os professores de educação física sentem dificuldade em se libertar de determinados preconceitos e propor uma prática que propicie as mesmas oportunidades a todos os alunos, meninos e meninas, respeitando as diferenças e os interesses de cada um (DAOLIO, 2003, p. 115).

\footnotetext{
${ }^{5}$ Ressaltamos que tal fato não está relegado somente à EF, pode-se afirmar que no seio de outras disciplinas também é hegemônica a explicação "naturalista" para a compreensão das diferenças. "Os meninos são melhores nos cálculos, pois tem raciocínio lógico-matemático mais desenvolvido, já as meninas são melhores na literatura e nas artes, pois são sensíveis por 'natureza'. Não foram poucas as vezes que foram ouvidas tais afirmações.

${ }^{6}$ Especificamente em Daolio (1995, 1998, 2003 e 2004), Soares et al (1992), Kunz (1991 e 1994), Betti (1992 e 1994) e Bracht (1992), dentre outros.

7 Trata-se do sujeito que, em termos populares, é "ruim" nos esportes, ou seja, não "leva jeito".

Movimento, Porto Alegre, v. 16, n. 01, p. 149-167, janeiro/março de 2010.
} 


\section{Astifor Orifinais Rogério Cruz de Oliveira e Jocimar Daolio}

Em relação ao sectarismo menino versus menina, destacamos Carolina. ${ }^{8}$ Podemos até dizer que, dentre todos da turma, ela é quem mais se destacava, pois, além de intensa participação, era extremamente "hábil" nos esportes. No entanto, toda a turma chamava-a de "gordinha". O destaque dado por nós à Carolina deve-se ao tripé excludente "ser menina, ser gordinha e ser 'hábil' nos esportes", fato que lhe rendeu comentários jocosos de muitos de seus colegas em todas as oportunidades observadas em que a aluna teve de se integrar a alguma atividade. Se Carolina jogava voleibol, os comentários pejorativos eram pelo fato de ser "gordinha". Logo após um lance num jogo de voleibol, uma menina pegou a bola e perguntou para as colegas, na ausência momentânea da professora: "Gente, qual a diferença entre a bola e os 'peitos' da gordinha? Não dá pra saber, né?!" (aos risos).

Notava-se que Carolina procurava não se aborrecer, dando pouca atenção aos comentários. Quando ela se propunha a jogar futebol, os comentários advinham do fato de ser menina e hábil. Nesta turma, tanto as meninas quanto os meninos não eram muito flexíveis à ideia de uma menina jogar futebol. ${ }^{9}$ No caso da $8^{\mathrm{a}} \mathrm{B}$, em nenhum momento as meninas jogaram futebol com os meninos e vice-versa. Talvez, na concepção da turma, o universo futebolístico reserve às meninas o papel de meras espectadoras. Durante todo o período de observação da pesquisa, as meninas da turma praticaram o futebol em apenas três oportunidades. Parecia que futebol de menina era uma prática de menor valor, relegada a um plano menos sério, portanto, merecedor de menores privilégios, estes dados aos meninos. Quanto à "habilidade" de Carolina nos esportes, esta característica era vista como masculinizante, não sendo bem-vinda numa menina.

\footnotetext{
${ }^{8}$ Para fins de preservação do anonimato dos participantes, utilizaremos pseudônimos quando formos referenciá-los.

9 Pode-se entender o fenômeno da "quase" exclusividade da prática do futebol pelos meninos nestas aulas a partir da assertiva de Moura (2005), que afirma que o futebol no Brasil é uma "área reservada masculina". Segundo o autor, o futebol, por ser um esporte de contato, está totalmente ligado ao estereótipo masculino, altivo e fisicamente forte, contrapondo-se ao feminino, representado como tímido, frágil e dependente. Nesse sentido, pode-se entender o porquê do papel coadjuvante das mulheres no universo futebolístico brasileiro e nas próprias aulas de EF. O estudo de Oliveira (2001, p. 136) traz um anúncio publicitário dos Jogos Colegiais de uma grande capital brasileira O cartaz trazia a seguinte frase: "Se você não ficou nem na reserva, esquente o banco da arquibancada" Além da "sonora" frase, o cartaz ainda trazia a figura de um "pompom", material tradicionalmente relacionado às mulheres nas torcidas.
}

Movimento, Porto Alegre, v. 16, n. 01, p. 149-167, janeiro/março de 2010. 
Outro personagem de destaque na tensa relação meninos versus meninas foi Eduardo. Este, sempre tratado pelos colegas como "biba", fato decorrente de seus gestos e comportamentos tradicionalmente relacionados ao gênero feminino, sempre esteve à margem da aula. Da mesma forma que Carolina, Eduardo era bastante participativo, no entanto, os comentários dirigidos a ele durante as aulas o fizeram, por diversas vezes, desistir da atividade. Outra característica que contribuía para que Eduardo ficasse à margem das aulas era o fato do mesmo ser o "grosso" da turma, tendo muita dificuldade na realização das práticas corporais propostas pela professora. Numa certa aula, Eduardo, que jogava voleibol, resolveu sair da quadra, tais eram as ofensas dirigidas a ele. Ele sentou-se ao lado da professora e se propôs a marcar os pontos. O fato de ter saído do jogo "tirou um peso" enorme de suas costas, parecia mais "tranquilo" do lado de fora.

Diante desse panorama, protagonizado por Carolina e Eduardo, entendemos que a concepção de menino e menina que subsidiava as ações dos atores sociais desta turma pautou-se em certa "naturalização" das diferenças entre ambos, como se estas fossem fruto apenas das composições biofisiológicas dos corpos masculino e feminino, o que constitui reducionismo. Segundo Mead (1971), a cultura sexual traça um estereótipo que separa, desde crianças, indivíduos que devem agir masculinamente ou femininamente conforme a sociedade em que estão inseridos.

Para Daolio (2003), há uma construção cultural específica do corpo masculino e do feminino. O autor ainda afirma que, sobre um menino, mesmo antes de nascer, recai toda uma expectativa de segurança e altivez de um macho que dará sequência à geração. Já no caso das meninas, afirma o autor, paira toda uma delicadeza e cuidados.

Neste estudo, Carolina e Eduardo sofreram limitações quanto às aulas por não se encaixarem em estereótipos esperados para uma menina e um menino, o que lhes rendeu desigualdades de acesso às práticas. Eduardo, ao não demonstrar a altivez característica de um menino na sua idade, nem mesmo habilidade nos esportes, não se enquadrava num "ideário" masculino. Da mesma forma, Carolina, não se encaixando num perfil dócil e passivo, não se enquadrava num "ideário" feminino, fatos esses suficientes para relegá-los ao plano inferior.

Movimento, Porto Alegre, v. 16, n. 01, p. 149-167, janeiro/março de 2010. 
158 Artifos Originais Rogério Cruz de Oliveira e Jocimar Daolio

No entanto, este estudo não se prendeu somente aos fatos ligados ao gênero. Outros aspectos saltaram aos nossos olhos, dos quais a habilidade nas práticas corporais desenvolvidas nesta turma foi merecedora de destaque.

Em relação à habilidade com a bola nos pés, o padrão deu-se pelas técnicas observadas no esporte profissional. Qualquer técnica ${ }^{10}$ empregada nos jogos, que fugiu ao padrão futebolístico dos grandes astros, foi motivo de piada ou, em alguns casos, fator determinante de menor participação no jogo desenvolvido. Quem era mais habilidoso, além de galgar maior status, participava mais do jogo, o contrário acontecendo para os "grossos". Conforme nos alerta Oliveira (2006), há aqui a compreensão de que a técnica certa é aquela do esporte profissional e a errada é qualquer outra que fuja a esse padrão.

Tal fato também pode ser percebido nas aulas de voleibol. A professora, mesmo permitindo flexibilização nas regras, intervinha o tempo todo no sentido de "corrigir" determinados gestos técnicos "desconcertantes". Assim, não houve valorização das "diferentes saídas" - leia-se técnicas - encontradas pelos alunos para solucionar um problema ou alguma situação do jogo.

Quando se elege/padroniza, seja no voleibol, seja no futebol, nas aulas de EF da $8^{\mathrm{a}} \mathrm{B}$ ou em qualquer outro lugar, uma determinada forma de jogar, acaba-se desvalorizando e inferiorizando determinados repertórios corporais, fomentando, assim, o surgimento de preconceitos e sectarismos, conforme observado neste estudo. Meninos e meninas que não jogavam "bem" ou eram "grossos", ou ainda, entendiam que não "levavam jeito", exerceram papel de coadjuvantes nas aulas ou, em alguns casos, nem chegaram a compor o "enredo" de determinadas práticas encenadas.

Outro fato que nos chamou a atenção foi a divisão dos grupos entre os meninos que jogavam o futebol. Ao iniciar a pesquisa, tínhamos a ideia de que tal divisão privilegiaria aqueles que mais se destacavam em termos de habilidade, o que de fato aconteceu em alguns casos,

${ }^{10}$ De acordo com Marcel Mauss (2003), entendemos a técnica como a maneira pela qual os seres humanos sabem servir-se de seus corpos.

Movimento, Porto Alegre, v. 16, n. 01, p. 149-167, janeiro/março de 2010. 
porém não se tratava de uma regra única. Além da habilidade, era necessário também certo "pertencimento" àquele grupo, que se dava pela "visibilidade" de algumas características, a saber: resistir à aula de voleibol - pois era "coisa de mulherzinha" -, hostilizar colegas com comentários pejorativos, não se misturar muito com as meninas e ser arredio com a professora. Nem todos tinham todas estas características mas pareciam pré-requisitos que legitimavam certo status entre os meninos.

Em relação ao preconceito relacionado aos negros, observamos uma situação em que este fato foi encenado. Numa certa aula, a professora propôs um jogo misto de voleibol, para desânimo de alguns. Mateus, um menino negro que tinha ficado de fora deste jogo para conversar com uma menina na arquibancada, sofria ofensas de seus colegas que jogavam. A ofensa que mais se repetiu foi chamar Mateus de "Maguila"11 e outras derivações, buscando fazê-lo desistir da aparente paquera e jogar, o que ocorreu em seguida. Em quadra, no decurso do jogo, Mateus errou um lance de finalização de uma jogada, fato suficiente para que um de seus colegas afirmasse veementemente e em alta voz: "É por isso que você é preto!"

Neste caso, o fato de ser negro imputou-o o rótulo de menos capaz, bem como, no entendimento de quem o ofendeu, de fator primordial para o "erro" da jogada. Como se o fato de ser negro tivesse alguma relação com o gesto técnico realizado. No entanto, o mesmo era ovacionado no futebol. Mas, por quê? Talvez pelo fato de ser habilidoso com a bola nos pés? É possível. Porém, percebemos que sua popularidade era tamanha no futebol nem tanto por sua habilidade mas pelo jeito "malandro" como jogava, jeito esse também estereotipadamente relegado aos negros, que, especificamente no Brasil, ainda levam o rótulo de apreciadores de samba e carnaval.

Segundo Candau (2002), essa é uma realidade muito presente no imaginário da sociedade em geral, que tende a classificar as pessoas segundo atributos considerados específicos de determinados grupos

\footnotetext{
${ }^{11}$ Aqui existem duas alusões preconceituosas: uma ao desenho animado de um macaco que se chamava Maguila e outra referente ao boxeador negro, Maguila. Lembramos também que a denominação do último também decorre do desenho animado referido.

Movimento, Porto Alegre, v. 16, n. 01, p. 149-167, janeiro/março de 2010.
} 
sociais. Trata-se de uma visão "engessada" de cultura, a qual denota a existência de fronteiras que separam, rigidamente, os grupos sociais pelas suas características visivelmente diferentes, o que acaba por escamotear toda uma realidade social e desconsiderar o processo dinâmico da cultura.

A nosso ver, as diferenças envolvem não somente as características mais visíveis dos sujeitos, mas também sua subjetividade, a forma como se relacionam, suas visões de mundo, enfim, conforme Gusmão (2003), em todas as dimensões da vida vivida, do nosso cotidiano e, até mesmo, onde sequer suspeitamos de sua existência.

Dessa forma, os dados apresentados neste estudo nos levam a entender que o Outro, visivelmente diferente, representou um Outro desigual, tolerado, porém estigmatizado. Um Outro inferior que, no expressar de suas diferenças, experimentou nítida desigualdade em suas interações.

\section{A ALTERIDADE E A EDUCAÇÃO INTERCULTURAL COMO POSSIBILIDADE}

Concluímos que: ao mergulharmos no cotidiano das aulas de EF de uma oitava série, buscando compreender como as diferenças são significadas e representadas pelos alunos, deparamo-nos com um quadro limitador e reducionista da compreensão do Outro.

As diferenças, ao serem "estilhaçadas", constituíram um grande mosaico de partes disformes, no qual cada pedaço esboçou seus preconceitos, cindindo e ignorando as diversas formas de estar, de pensar e de viver o mundo. Não se considerou, portanto, que a forma como as diversas pessoas vivem e/ou se expressam, fazem parte de apenas um, dentre vários possíveis, padrões culturais.

Neste estudo, os preconceitos, as desigualdades - tanto de acesso quanto de participação nas aulas - e os sectarismos percebidos tiveram gênese na manifestação de certas diferenças apresentadas pelos atores sociais, não tendo sido compreendidas no todo complexo que envolve as relações sociais. Ser gordinha, negro, "grosso" ou, simplesmente, demonstrar gestos e comportamentos relacionados ao outro

Movimento, Porto Alegre, v. 16, n. 01, p. 149-167, janeiro/março de 2010. 
gênero, como no caso de Eduardo, determinou o grau de envolvimento e pertencimento à aula, bem como o encenar de certas privações.

\begin{abstract}
Quando as diferenças culturais são consideradas numa perspectiva estereotipada, focaliza-se apenas as manifestações externas e particulares dos fenômenos culturais. Deixa-se valorizar devidamente os sujeitos sociais que produzem tais manifestações culturais, ou não se consegue compreender a densidade, a dinamicidade e a complexidade dos significados que eles tecem (FLEURI, 2003, p. 24).
\end{abstract}

Atualmente, endossar a valorização e o respeito às diferenças na educação e na EF parecem não causar mais tanta resistência. No entanto, é preocupante imaginar que o cenário escolar ainda encontra-se permeado por concepções que tangenciam certos ranços naturalistas que, ao serem sinalizados nesta pesquisa, alcançam proporções que deflagram preconceitos, sectarismos e desigualdades de oportunidades.

Assim, entendemos, de acordo com Fleuri (2003), que se faz necessário nos aventurarmos no encontro com a alteridade. Entender que existem diferentes formas de se expressar no mundo, pensá-lo, vivê-lo e nele atuar e que Eduardo ou Carolina, ou qualquer outro personagem deste enredo, não são mais ou menos iguais, mas, sim, diferentes. E, como tais, também têm algo a contribuir com o outro.

Desse modo, concordando com Oliveira (2006), entendemos residir na alteridade e nos pressupostos da educação intercultural uma possibilidade de enfrentamento das desigualdades de oportunidades, estereótipos, preconceitos e sectarismos ainda diluídos nos cotidianos escolares. Cientes de possíveis limitações mas conscientes de que se trata de um ponto de partida para se pensar outro tipo de relação social em qualquer cenário escolar.

Assim, a alteridade coloca-se na direção de um caminho possível de enfrentamento das tensões advindas da diversidade cultural, percebidas neste estudo.

A alteridade revela-se no fato de que o que eu sou e o outro é não se faz de modo linear e único, porém constitui um jogo de imagens múltiplo e diverso.

Movimento, Porto Alegre, v. 16, n. 01, p. 149-167, janeiro/março de 2010. 
162 Artifos Originais Rogério Cruz de Oliveira e Jocimar Daolio

Saber o que eu sou e o que o outro é depende de quem eu sou, do que acredito que sou, com quem vivo e por quê. Depende também das considerações que o outro tem sobre isso, a respeito de si mesmo, pois é nesse processo que cada um se faz pessoa e sujeito, membro de um grupo, de uma cultura e uma sociedade. Depende também do lugar a partir do qual nós nos olhamos. Trata-se de processos decorrentes de contextos culturais que nos formam e informam, deles resultando nossa compreensão de mundo e nossas práticas frente ao igual e ao diferente (GUSMÃO, 2003 , p. 87 , grifos da autora).

Neste sentido, a educação intercultural pronuncia-se. Tais pressupostos caminham na direção do entendimento de que existem diferenças e que estas, necessariamente, devem compor o quadro de aprendizagem do educando, proporcionando o contato com o "outro", com o "diferente" e que com ele estabeleça um diálogo profícuo e mútuo, no qual as possibilidades não se encerram a partir de uma única visão.

A educação, na perspectiva intercultural, deixa de ser assumida como um processo de formação de conceitos, valores, atitudes, baseando-se numa relação unidirecional, unidimensional e unifocal, conduzida por procedimentos lineares e hierarquizantes. A educação passa a ser entendida como o processo construído pela relação tensa e intensa entre diferentes sujeitos, criando contextos interativos que, justamente por se conectar dinamicamente com os diferentes contextos culturais em relação aos quais os diferentes sujeitos desenvolvem suas respectivas identidades, torna-se um ambiente criativo e propriamente formativo, ou seja, estruturante de movimentos de identificação subjetivos e socioculturais (FLEURI, 2003, p. 31-32, grifos do autor).

Nessa perspectiva, as diferenças seriam encenadas com outro enredo. Um enredo que, ao invés de estabelecer desigualdades de oportunidades, no caso de Eduardo e Carolina, proporcionaria igualdades de acesso, no entanto, sem homogeneizar os personagens, pelo contrário, encontrando nas suas diferenças o ponto de partida para um diálogo profícuo; um enredo que, ao invés de palco de preconceitos e

Movimento, Porto Alegre, v. 16, n. 01, p. 149-167, janeiro/março de 2010. 
subjugações, no caso de Mateus, seria palco de nova compreensão das diferenças e aprendizado com o diferente; enfim, um enredo que, ao invés de estabelecer certos sectarismos, proporcionaria um compartilhar democrático (OLIVEIRA, 2006).

No entanto, ressaltamos que o caminho para as ressignificações na compreensão das diferenças é movediço e propenso a certas armadilhas. Ou seja, se não consideradas com certo "cuidado", corre-se risco de banalização dos "outros", relativismos extremos, universalismos absolutos ou novas submissões e subjugações.

Há de se considerar também que a EF acontece nas escolas sob a expectativa de certa tradição. Aulas esportivas de cunho predominantemente vivencial que, pela "natureza" dos educandos - meninos e meninas - deve ser ofertada de maneira distinta, a fim de preservar suas características. Se este script for "radicalmente" negado, dando lugar a uma prática distante do roteiro previsto, pode acontecer uma resistência tão grande por parte dos alunos que inviabilizaria qualquer tentativa de mudança. No entanto, o contrário também não seria desejável: uma vez reforçada a tradição, as possibilidades de novos reordenamentos se perderiam. Frente ao impasse, aonde residiria a possibilidade? Pensamos que no diálogo, moldado a partir do que afirmou a professora: "É preciso ter paciência e perseverança".

Tal ação (diálogo), dando-se entre professores e alunos, e entre estes, possibilitaria o que, frequentemente, foi negado nas relações sociais observadas nas aulas de EF deste estudo: a troca, o compartilhar. Mas não um compartilhar banal, no sentido de somente saber o que o "outro" é, conhecê-lo e tolerá-lo, mas num sentido mais amplo, de aprender com esse "outro". Possibilitar o entendimento de que existem diferenças e que elas compõem o quadro da humanidade. $\mathrm{O}$ "outro" constitui-se num possível "eu”.

Isso porque, concordando com Fleuri (2003, p. 32), embasado em Paulo Freire, "[...] as pessoas se educam em relação, mediatizadas pelo mundo, ao mesmo tempo em que seus respectivos mundos culturais e sociais se transformam, mediatizados pelas próprias pessoas em relação."

Movimento, Porto Alegre, v. 16, n. 01, p. 149-167, janeiro/março de 2010. 
164 Artigos Originais Rogério Cruz de Oliveira e Jocimar Daolio

Por ora, entendemos que o debate merece maiores aprofundamentos e novos questionamentos que, ao serem sinalizados neste estudo, vislumbram uma prática educativa ressignificada de valores, atitudes, posicionamentos e entendimentos na direção do diálogo e da alteridade, o que, para além de relevante, torna-se necessário.

Movimento, Porto Alegre, v. 16, n. 01, p. 149-167, janeiro/março de 2010. 


\begin{tabular}{l}
\hline Physical Educatioin, culture and school: from \\
difference as inequality to alterity as possibility. \\
Abstract: This study aims to comprehend how diffe- \\
rences are signified and represented by students in \\
Physical Education classes. It is an ethnography con- \\
ducted in a State school in the municipality of Campinas, \\
SP. Such an incursion led us to the understanding that \\
the differences presented by the students constituted \\
parameters to define inequality of opportunity, prejudices \\
and sectarianisms. Thus, the understanding of diffe- \\
rences was permeated by an amount of reductionism, \\
as they perceived the "other" only through her/his most \\
conspicuous characteristics, clouding the complexity \\
of the cultural dynamics. Finally, we understand that it \\
is desirable for differences to be considered within the \\
vision of alterity, aided by a cross-cultural perspective of \\
education. \\
Keywords: Physical Education. Education. Prejudice. \\
Gender identity.
\end{tabular}

\begin{tabular}{l}
$\begin{array}{l}\text { Educación Física, cultura y escuela: de la dife- } \\
\text { rencia como desigualdad a la alteridad como } \\
\text { posibilidad. } \\
\text { Resumen: Este estudio tiene el objetivo de comprender } \\
\text { como las diferencias son significadas y representadas } \\
\text { por los alumnos en clases de Educación Física. Se trata } \\
\text { de una etnografía conducida en una escuela pública en } \\
\text { la municipalidad de Campinas, SP. Tal incursión nos llevó } \\
\text { a la comprensión de que las diferencias presentadas } \\
\text { por los alumnos constituyeron parámetros definidores } \\
\text { de desigualdad de oportunidades, prejuicios y secta- } \\
\text { rismos. Así, el entendimiento de las diferencias estuvo } \\
\text { impregnado por ciertos reducciones, percibiendo al 'otro' } \\
\text { únicamente por sus características más visibles, obscu- } \\
\text { reciendo la complejidad de la dinámica cultural. Por fin, } \\
\text { comprendemos que es deseable que las diferencias } \\
\text { sean consideradas en la óptica de la alteridad subsi- } \\
\text { diada por una perspectiva intercultural de educación. } \\
\text { Palabras clave: Educación Física. Educación. Prejuicio. } \\
\text { Identidad de género. }\end{array}$ \\
\hline
\end{tabular}

\section{REFERÊNCIAS}

AYOUB, Eliana. Memórias da educação física escolar. In: CONGRESSO BRASILEIRO DE CIÊNCIAS DO ESPORTE, 14.; CONGRESSO INTERNACIONAL DE CIÊNCIAS DO

Movimento, Porto Alegre, v. 16, n. 01, p. 149-167, janeiro/março de 2010. 
166 Astifos Originais Rogério Cruz de Oliveira e Jocimar Daolio

ESPORTE, 1., 2005, Porto Alegre. Anais... Porto Alegre: MFPA, 2005. 1 CDROOM. p. $2260-2270$.

BETTI, Mauro. Ensino de primeiro e segundo graus: educação física para quê? Revista Brasileira de Ciências do Esporte, Maringá, v. 13, n. 2, p. 282-287, 1992.

Valores e finalidades na educação física escolar: uma concepção sistêmica. Revista Brasileira de Ciências do Esporte, Santa Maria, v. 16, n. 1, p. 14-21, 1994

BRACHT, Valter. Educação física e aprendizagem social. Porto Alegre: Magister, 1992.

CANDAU, Vera Maria Ferrão. Sociedade, cotidiano escolar e cultura (s): uma aproximação. Educação e Sociedade, Campinas, v. 23, n. 79, p. 125-161, ago. 2002.

DAOLIO, Jocimar. Cultura, educação física e futebol. 2. ed. Campinas: Unicamp 2003.

Da cultura do corpo. Campinas: Papirus, 1995

Educação física brasileira: autores e atores da década de 1980. Campinas: Papirus, 1998. 2004.

Educação Física e o conceito de cultura. Campinas: Autores Associados,

DAUSTER, Tânia. Construindo pontes - a prática etnográfica e o campo da educação. In: DAYRELL, Juarez. (Org.). Múltiplos olhares sobre educação e cultura. Belo Horizonte: UFMG, 1996. p. 65-72.

FLEURI, Reinaldo Matias. Intercultura e educação. Revista Brasileira de Educação, Rio de Janeiro, n. 23, p. 16-35, 2003.

FONSECA, Cláudia. Quando cada caso NÃO é um caso: pesquisa etnográfica e educação. Revista Brasileira de Educação, Rio de Janeiro, n. 10, p. 58-78, jan./abr. 1999.

GEERTZ, Clifford. A interpretação das culturas. Rio de Janeiro: Guanabara Koogan 1989.

GUSMÃO, Neusa Maria Mendes de. Os desafios da diversidade na escola. In: GUSMÃO, Neusa Maria Mendes de (Org.). Diversidade, cultura e educação: olhares cruzados. São Paulo: Biruta, 2003. p.83-106.

KUNZ, Elenor. Educação física: ensino e mudanças. ljuí: Unijuí, 1991.

Transformação didático-pedagógica do esporte. Ijuí: Unijuí, 1994.

MAGNANI, José Guilherme Cantor. De perto e de dentro: notas para uma antropologia urbana. Revista Brasileira de Ciências Sociais, São Paulo, v. 17, n. 49, p. 11-29, jun. 2002.

Vovimento, Porto Alegre, v. 16, n. 01, p. 149-167, janeiro/março de 2010. 
MAUSS, Marcel. Sociologia e antropologia. São Paulo: EDUSP, 2003.

MEAD, Margaret. Macho e fêmea: um estudo do sexo num mundo em transformação. Petrópolis: Vozes, 1971

MOURA, Eriberto Lessa. O futebol como área reservada masculina. In: DAOLIO, Jocimar. (Org.). Futebol, cultura e sociedade. Campinas: Autores Associados, 2005. p. 131-147.

OLIVEIRA, Rogério Cruz de. Educação física, escola e cultura: o enredo das diferenças. 2006. 101f. Dissertação (Mestrado em Educação Física) - Faculdade de Educação Física. Universidade Estadual de Campinas, Campinas, 2006.

OLIVEIRA, Rogério Cruz de; DAOLIO, Jocimar. Pesquisa etnográfica em educação física: uma (re)leitura possível. Revista Brasileira de Ciência e Movimento, Brasília, v. 15, n. 1, p. 137-143, mar. 2007.

OLIVEIRA, Sávio Assis de. Reinventando o esporte: possibilidades da prática pedagógica. Campinas: Autores Associados, 2001.

ORTIZ, Renato. Um outro território: ensaios sobre a mundialização. São Paulo: Olho d'água, 2000

SARAIVA, Maria do Carmo. Co-educação física e esportes: quando a diferença é mito. 2. ed. ljuí: Unijuí, 2005.

SOARES, Carmem Lúcia; TAFFAREL, Celi Nelza Zülke; VARJAL, Elizabeth; CASTELLANI FILHO, Lino; ESCOBAR, Micheli Ortega; BRACHT, Valter. Metodologia do ensino da educação física. São Paulo: Cortez, 1992.

Movimento, Porto Alegre, v. 16, n. 01, p. 149-167, janeiro/março de 2010. 